\title{
Use of Self-Created Videos for Teaching Structured Query Language (SQL) using Flipped Classroom Activity
}

\author{
Sunita M Dol \\ Computer Science and Engineering Department, Walchand Institute of Technology, Solapur, India \\ sunita_aher@yahoo.com
}

\begin{abstract}
Active learning strategy is an approach to teaching and learning whose goal is to engage students with the content via specific activities designed by the instructor that get students to talk, write, reflect and express their thinking. So active learning strategy is basically getting the students to engage with the content, getting them to do some activity in the classroom and discover how much they have understood. There are various active learning strategies like Think-Pair-Share, Peer Instruction, TeamPair-Solo, Flipped classroom, etc. In current study, the flipped classroom activity with Think-Pair-Share, Peer Instruction and Team-Pair-Solo as In-class activities are considered. The Learning Outcome of this activity is: Students will be able to create, alter or drop relation in the database for given application using Data Definition Language commands CREATE, ALTER and DROP. The assignment submission result showed the significantly good result.
\end{abstract}

Keywords: Database Engineering(DBE), Structured Query Language (SQL),Peer Instruction, Flipped Classroom, Think-Pair-Share, Team-Pair-Solo, Blooms' Taxonomy.

\section{Introduction}

Now days it is required to provide students with alternative methods in addition the traditional method like blackboard teaching method of learning in teaching-learning process (Htwe and et. al., 2012). Pahwa and Mills (Saxena and et. al., 2009) found that incorporation of active learning strategies into the curriculum can improve understanding and learning about the course. Active-learning strategies used into classroom allows instructor to engage students in the learning process and make their learning experience more effective, efficient and meaningful (B. Graffam, 2007).

\author{
S. M. Dol \\ Computer Science and Engineering Department, Walchand \\ Institute of Technology, Solapur, India \\ sunita_aher@yahoo.com
}

Introduction of active learning strategies in the teachinglearning process provides instructors with an opportunity to engage all students in the class and enhance their learning process (C.M. Bailey and et.al., 1999; J. R. Dimmock, 2000; V. F. Rochend et. al.,2004). Michael Prince (Michael Prince , 2004) also examined the evidence for the effectiveness of active learning in teaching-learning process. There are various active learning strategies Think-PairShare, Peer Instruction, Team-Pair-Solo, Flipped classroom, etc. In current study, flipped classroom activity is used for the topic- Structured Query Language of Database Engineering. In this activity, self created videos are used for out-of-class activity.

\section{Related Work}

There is extensive research in the educational field related to the active learning strategies like Think-Pair-Share (Sunita B. Aher and Dattatray P Gandhmal, 2014; Sunita M Dol, 2014; Sunita M Dol, 2017) Peer Instruction, TeamPair-Solo, Flipped classroom, Gamification, project based learning, mobile based learning (Sunita M Dol and P. S. R. Patnaik, 2017), game and puzzle based learning (Sunita M Dol, 2017), handout based learning (Sunita M Dol and Trupti S Indi, 2017; Trupti S. Indi and Sunita M Dol, 2017 ), etc.

Zamzami Zainuddin and Siti Hajar Halili (Zamzami Zainuddin and Siti Hajar Halili, 2016) analysed the trends and contents of flipped classroom research based on 20 articles that report on flipped learning classroom initiatives from 2013-2015 while Sara Arnold-Garza (Sara ArnoldGarza , 2014) describes many of the characteristics of the flipped classroom teaching model, illustrated with examples from current higher education and library instruction literature. 
The study (Lynne Drake , 2016) analyzed the effectiveness in flipping thirty percent of the course content. The flipped classroom is used to teach various courses like math (Jeanette Villanueva), economics (Donna Feledichuk \& Andrew Wong), etc.

Think-Pair-Share active learning strategy is useful technique because of its benefits of allowing students to express their reasoning, reflect on their thinking, and obtain immediate feedback on their understanding (Aditi Kothiyal et. al.). This activity is useful for the courses like Theory of Computation (Sunita M Dol, 2014). The modified TPS activities like T24S (Sunita M Dol and Dr. S. A. Halkude, 2017, (Sunita M Dol and Dr. S. A. Halkude, 2017; Sunita

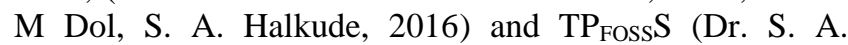
Halkude and Sunita M. Dol, 2017) are also useful for Theory of Computation. TP $\mathrm{TPSSS}_{\mathrm{S}}$ activity which is employed only to those courses for which free open source simulation software are available is also useful for teaching Compiler Construction course (Sunita B. Aher and Dattatray P Gandhmal, 2014).

The article (Trisha Vickrey and et.al., 2015) reviewed and summarized various bodies of research and provided instructors and researchers with a research-based model for the effective implementation of Peer Instruction which an example of an evidence-based instructional practice that consists of asking students conceptual questions during class time and collecting their answers via clickers or response cards. This activity is used by various researchers for the courses like physics (Ping Zhang and et.al, 2017; Tolga Gok, 2012) chromatography (J. Morice and et.al., 2015), etc.

In this article, active learning strategies Think-Pair-Share, Peer Instruction and Team-Pair-Solo are used while implementing the flipped classroom activity for the course Database Engineering.

\section{Structure of Self-Created Videos}

Each video consist of

- Front Slide

- Learning Outcomes

- Contents of topic

- Reflection Spot

- Explanation of Reflection Spot Question(s)

- Topic continuation followed by Assignment or Assignment

- References

Each video is of length 8-12 minutes.

\section{A. Front Slide}

This slide contains topic name, instructor introduction, college logo and Creative Common License. All these videos created are licensed under a Creative Commons Attribution $4.0 \quad$ International License https://creativecommons.org/licenses/by/4.0/.

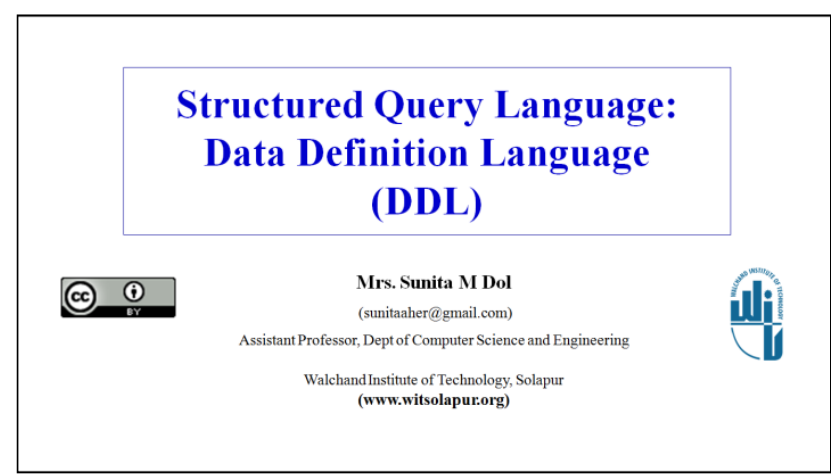

B. Learning Outcomes (LOs)

Learning outcome are statements that describe the learning that learners have achieved. These LOs are used to identify what the learner will know and be able to do by the end of a course or program.

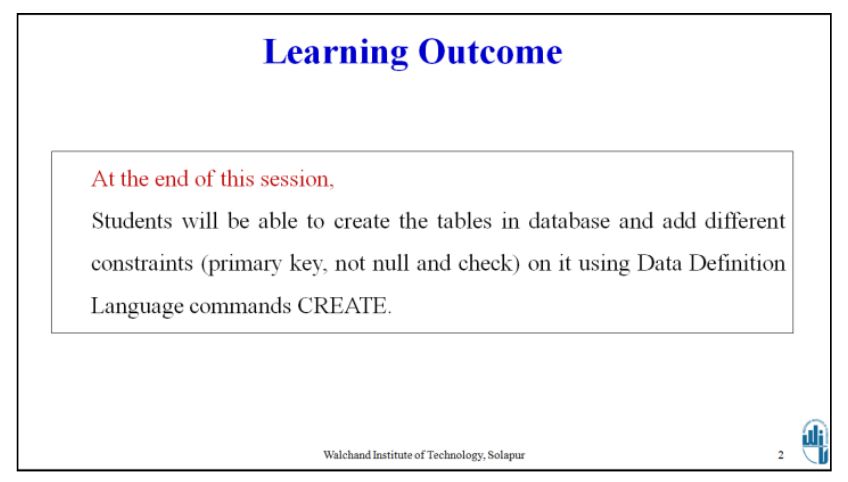

C. Contents of the topic

After covering the Learning Outcome, the contents of the topic is covered.

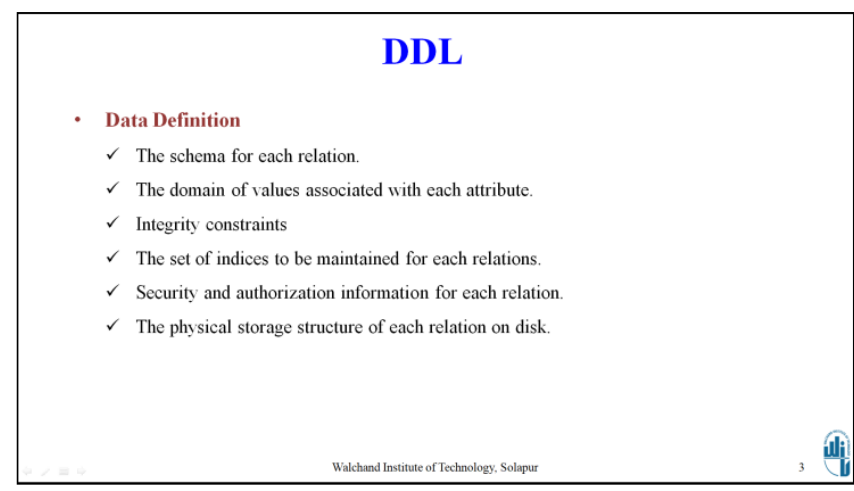

D. Reflection Spot

Each video has a reflection spot (reflection question), so that the participants can reflect on the content of video and express their thinking. Reflection spot question can be Multiple Choice Questions, Short Answer Questions, etc. 


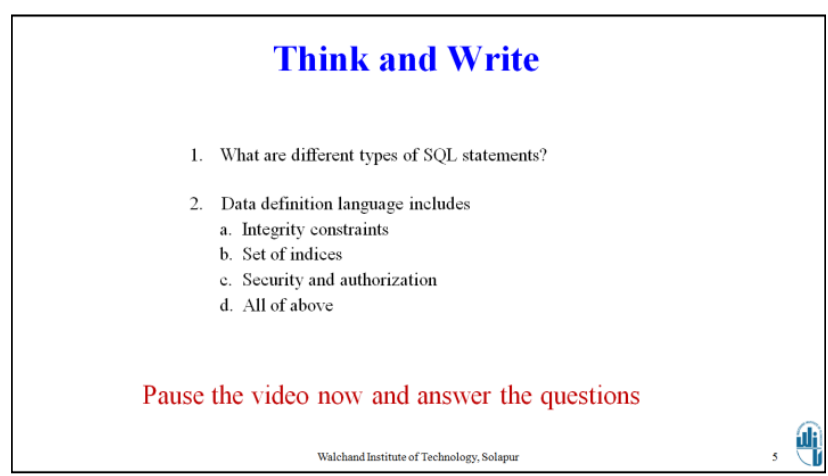

E. Explanation of Reflection Spot Question(s)

After asking the question in reflection spot on the covered topic, the explanation about the correct option is discussed.

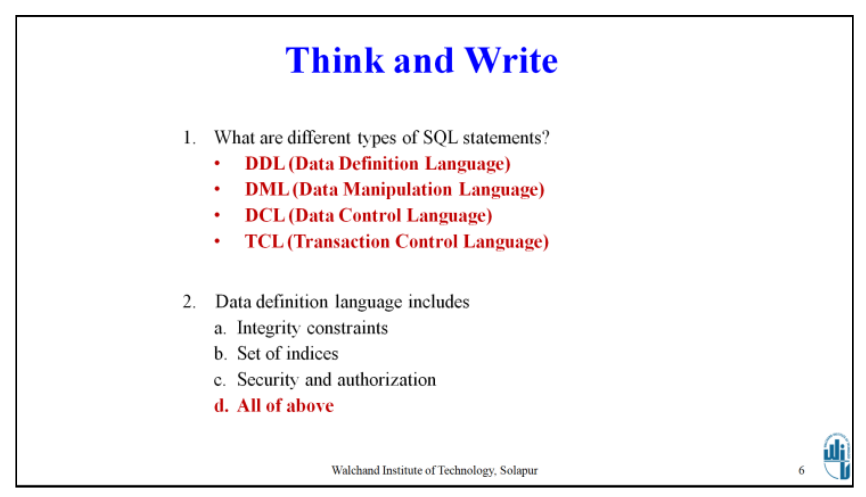

F. Topic continuation followed by Assignment or Assignment

After discussing the correct option of Reflection spot, either continuing topic followed by Assignment is considered or simply Assignment is considered.

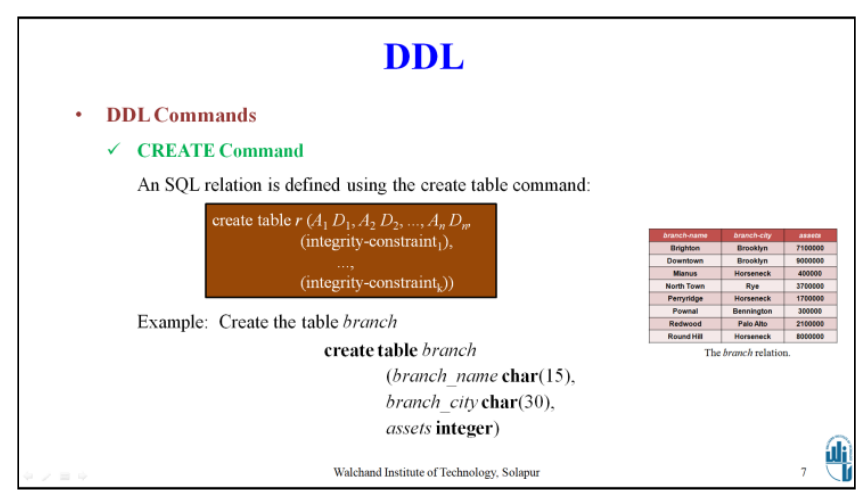

Each video contains the assignment on the covered topic in the video. In this slide, the learning outcomes must be matched with the question asked in the assignment. Every student has to submit this assignment as a part of out-ofclass activity of flipped classroom before coming to the class for in-class-activity.

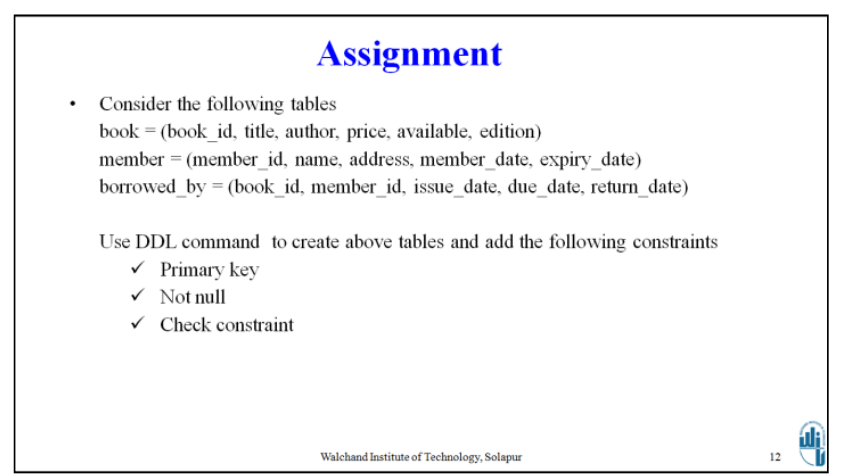

\section{G. References}

Each video also contains the references from which site or book, material in the slide is referred.

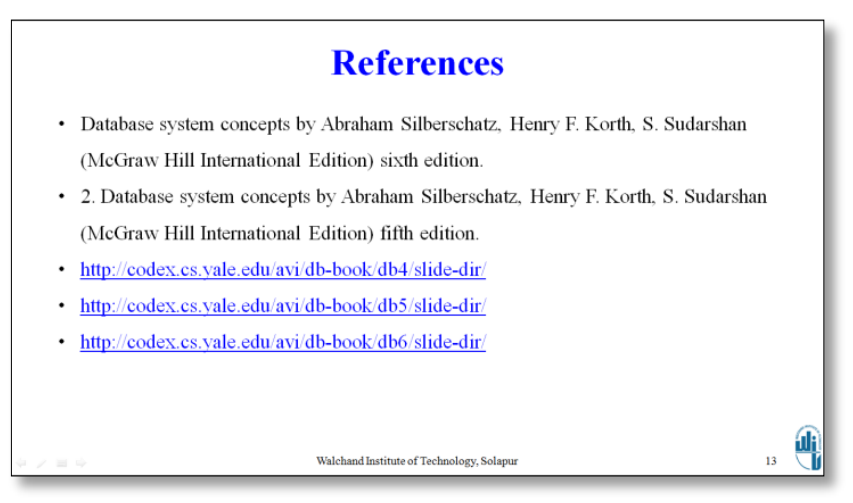

\section{Methodology used}

A. Sample

As Database Engineering (DBE) is the course of third year Computer Science and Engineering, so we consider 40 students.

B. Experimental Details

Experimental details for flipped classroom activity for SQL are given in the following figure 1. The steps are shown below:

Step 1: Instructor prepares the course material video as per the instruction in the section- Structure of Video and distribute the videos to the students for watching it at home.

Step2: Students go through the videos, think on the question asked in reflection spot and write the response to the question.

Step3: Students prepare the solution to the assignment asked in the video.

Step 2 and step 3 forms out-of-class activity for flipped classroom activity and this activity covers recall, understand and apply level of cognitive domain of Bloom's Taxonomy. 
Step 4: Students submit the completed assignment given in the video in the classroom.

Step 5: In in-class activity in the classroom, instructor consider the activity learning strategies like Think-Pair-
Share, Peer Instruction, etc. for better understanding of the content.

Step 4 and step 5 forms in-class activity for flipped classroom activity and this activity covers analyze, evaluate and create level of cognitive domain of Bloom's Taxonomy.

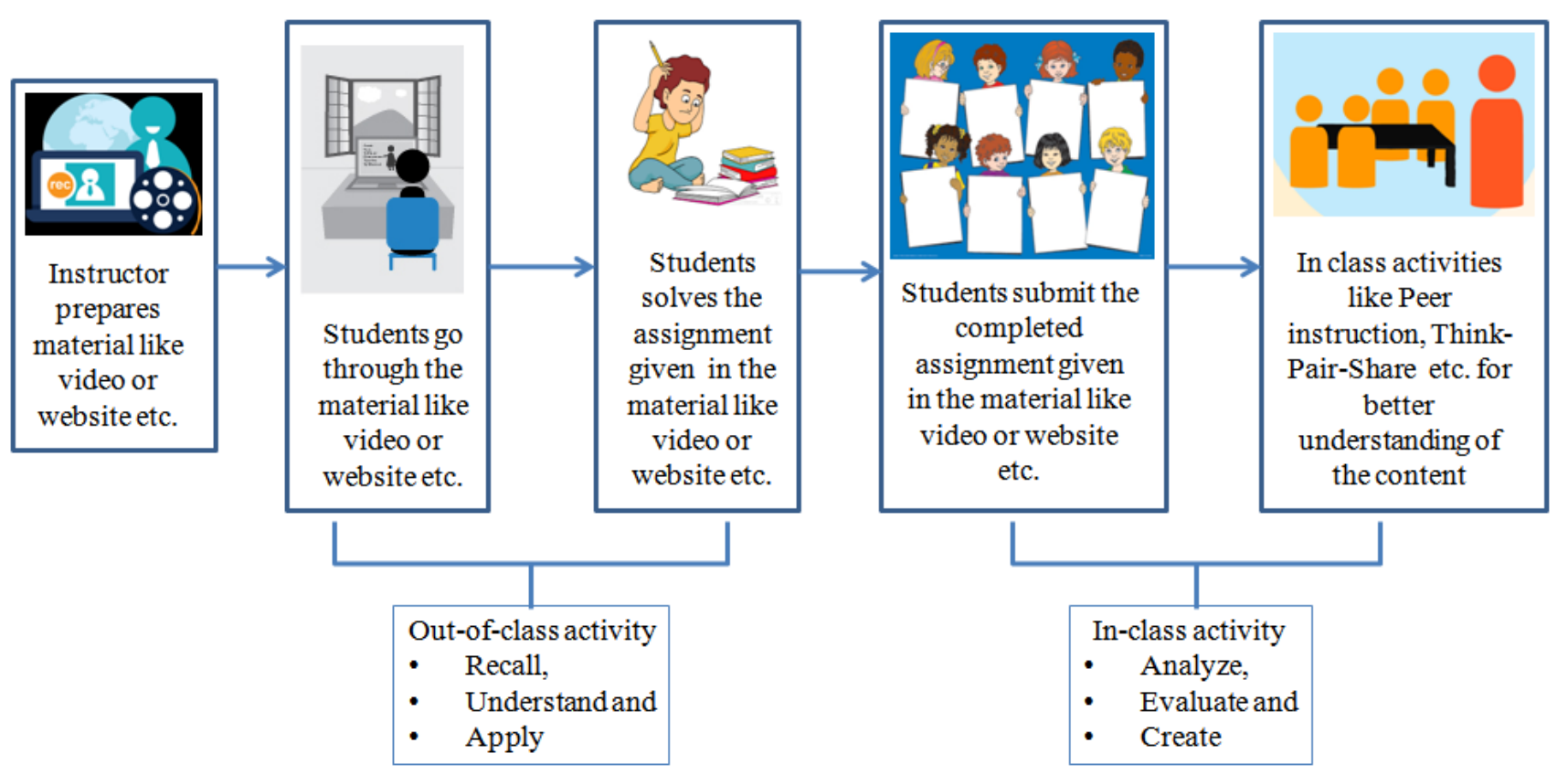

Fig. 1 Flipped Classroom Activity for SQL

C. Learning Objectives (LOs)

Learning objective of this flipped classroom activity is:

- Students will be able to create, alter or drop relation in the database for given application using Data Definition Language commands CREATE, ALTER and DROP

\section{Out of Class Activity}

Video URL, Learning Outcomes (Los), Kay concepts and assignments for Out-of-Class activity are given in the table1.

Table 1. Out of Class Activity Videos and Details

\begin{tabular}{|c|c|c|c|c|}
\hline $\begin{array}{l}\text { Sr. } \\
\text { No. }\end{array}$ & Video URL & Learning Outcomes (Los) & Kay concepts & Assignments \\
\hline 1 & $\begin{array}{l}\frac{\text { https://www.yo }}{\text { utube.com/wat }} \\
\text { ch?v=BGiIZgw } \\
\underline{9 \mathrm{JHY}}\end{array}$ & $\begin{array}{l}\text { Students will be able to create the } \\
\text { tables in database and add } \\
\text { different constraints (primary key, } \\
\text { not null and check) on it using } \\
\text { Data Definition Language } \\
\text { commands CREATE. }\end{array}$ & $\begin{array}{l}\text { CREATE } \\
\text { command } \\
\text { Primary key, } \\
\text { not null and } \\
\text { check } \\
\text { constraints }\end{array}$ & $\begin{array}{l}\text { Consider the following tables } \\
\text { book = (book_id, title, author, price, available, edition) } \\
\text { member = (member_id, name, address, member_date, expiry_date) } \\
\text { borrowed_by = (book_id, member_id, issue_date, due_date, return_date) } \\
\text { Use DDL command to create above tables and add the following } \\
\text { constraints } \\
\checkmark \quad \text { Primary key } \\
\checkmark \text { Not null } \\
\checkmark \text { Check constraint }\end{array}$ \\
\hline 2 & $\begin{array}{l}\frac{\text { https://www.yo }}{\text { utube.com/wat }} \\
\text { ch?v=64XfUvd } \\
\underline{\text { noHc }}\end{array}$ & $\begin{array}{l}\text { Students will be able to create the } \\
\text { tables in database and add } \\
\text { different constraints (foreign key, } \\
\text { unique and default) on it using } \\
\text { Data Definition Language } \\
\text { commands CREATE. }\end{array}$ & $\begin{array}{l}\text { CREATE } \\
\text { command } \\
\text { foreign key, } \\
\text { unique and } \\
\text { default } \\
\text { constraints }\end{array}$ & $\begin{array}{l}\text { Consider the following tables } \\
\text { book = (book_id, title, author, price, available, edition) } \\
\text { member = (member_id, name, address, member_date, expiry_date) } \\
\text { borrowed_by = (book_id, member_id, issue_date, due_date, return_date) } \\
\text { Use DDL command to create above tables and add the following } \\
\text { constraints } \\
\checkmark \text { foreign key, } \\
\checkmark \quad \text { unique and } \\
\checkmark \quad \text { default }\end{array}$ \\
\hline
\end{tabular}




\begin{tabular}{|c|c|c|c|c|}
\hline 3 & $\begin{array}{l}\frac{\text { https://www.yo }}{\text { utube.com/wat }} \\
\text { ch?v=JjUOIUR } \\
\underline{\text { s3u4 }}\end{array}$ & $\begin{array}{l}\text { Students will be able to alter/ } \\
\text { modify the database using Data } \\
\text { Definition Language commands } \\
\text { ALTER and DROP }\end{array}$ & $\begin{array}{l}\text { ALTER } \\
\text { command } \\
\text { DROP } \\
\text { command }\end{array}$ & 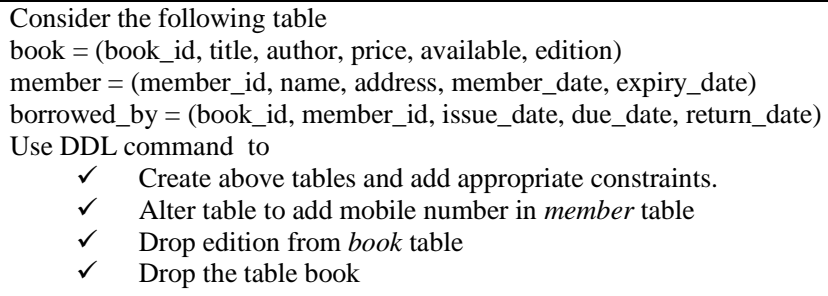 \\
\hline
\end{tabular}

E. In-Class Activity

1) In-Class Activity for Video 1: Learning Outcome (Los) for In-Class activity:

- Students will be able to create the tables for given application and add different constraints (primary key, not null and check) on it using Data Definition Language commands CREATE.

Key Concepts covered for the activity are:

- CREATE command

- $\quad$ Primary key, not null and check

Active Learning Strategy considered:

Peer instruction is an interactive teaching method which uses peer discussion as a way for students to deepen their understanding of a concept by learning from each other.

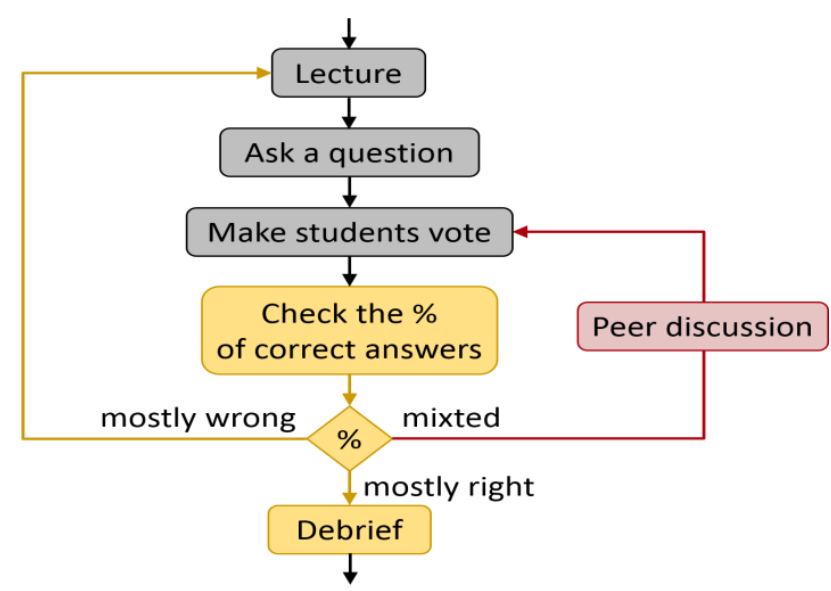

Fig. 2 Peer Instruction [source https://clickers.epfl.ch/interactionstrategies ]

Step 1: Iinstructor asked the question on the topic taught in the class.

Step 2: Students responds indidually.

Step 3: Instructor check the number of correct answer.

Step 4: If none or few students are answered correctly then

a. Iinstructor revisit the concept in the class

b. Go to step 1 .

Step 5: If some students are answered correctly then

a. Student turn to the neighbour and discuss the answer

b. Students respond again to the question asked instructor in step 1.

c. Instructor or group of students explain the answer to the question.

d. Instructor explain the remaining misconception and go to next topic.
Step 6: If most/ all students are answered correctly then

a. Instructor explain the remaining misconception and go to next topic.

Peer instruction questions sample is given below:

1. Consider the database given below

Product $=$ (product_id, product_name, quantity_per_unit, unit_price, unit_in_stock, units_on_order)

What are the different constraints that can be considered on the relation product?

a) Primary key, not null, check

b) Primary key, not null

c) Primary key, check

d) Primary key

2. Consider the database given below Product $=$ (product_id, product_name, quantity_per_unit, unit_price, unit_in_stock, units_on_order)

Which of the attributes can be considered for check constraints?

a) quantity_per_unit, unit_price, unit_in_stock,

b) quantity_per_unit, unit_in_stock, units_on_order

c) quantity_per_unit, unit_price, unit_in_stock, units_on_order

d) unit_price, unit_in_stock, units_on_order

2) In-Class Activity for Video 2: Learning Outcome (LOs) for In-Class activity:

- Students will be able to create the tables in database and add different constraints (foreign key, unique and default) on it using Data Definition Language commands CREATE.

Key Concepts covered for the activity are:

- CREATE command

- foreign key, unique and default

Active Learning Strategy considered:

In Team-Pair-Solo, students work in the group of four to solve the problem statement. Next teams break into pair to work on the same problem statement. Finally pair breaks up and student work individually to complete the task. 


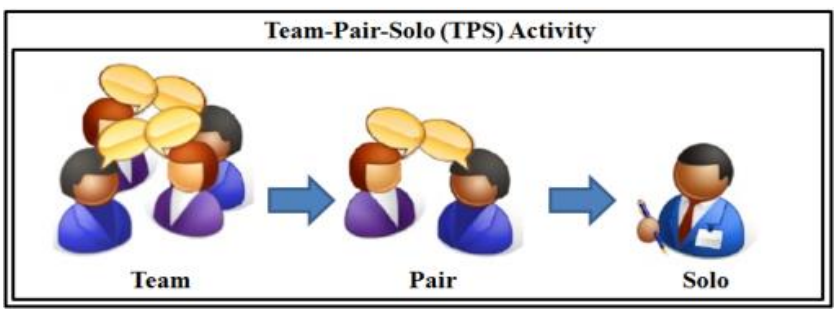

Fig. 3 Team-Pair-Solo Activity

Team pair solo activity considered is given below:

Consider the application and identify the at least two entity set and add different constraints (foreign key, unique and default) on it using Data Definition Language commands CREATE.

Product and Supplier

Team Phase: Identify the application and at least two entity sets.

Pair phase: Identify the different constraints that can be added on the entity set discussed in Team phase

Solo phase: Write the CREATE command to create the relations for entity sets considered in the Pair phase.

3) In-Class Activity for Video 3: Learning Outcome (Los) for In-Class activity:

- Students will be able to alter/ modify the database using Data Definition Language commands ALTER and DROP

Key Concepts covered for the activity are:

- ALTER command

- $\quad$ DROP command

Active Learning Strategy considered:

Think-Pair-Share TPS activity consists of three phases: Think, Pair and Share. So in TPS activity, students work on a problem posed by instructor, first individually (Think), then in pairs (Pair) and finally together with the entire class (Share). This activity develops soft skills, promotes confidence, self learning \& critical thinking ability.

Consider the entities Product and Supplier

Think Phase: Which attributes can be added to the relation product and supplier

Pair phase: Pair and share the solution to the question asked in Think Phase. Use command ALTER and DROP to add or drop the necessary attributes

Share phase: Share the solution in the class

\section{In-Class Activity for Video Overall}

Learning Outcomes (Los) for In-Class activity:

- Students will be able to create, alter or drop relation in the database for given application using Data Definition Language commands CREATE, ALTER and DROP

Key Concepts covered for the activity are:

- CREATE command

- ALTER command

- DROP command

Active Learning Strategy Considered:

T21S activity is considered for the In-Class activity. In $\mathrm{T} 21 \mathrm{~S}$, students work in the group of four to solve the problem statement. Next, teams splits into pair to work on the same problem statement. Finally pair breaks up and student work individually to complete the task followed by sharing of the problem statement solution with the class.

The four in group phase in the T24S activity works best for problem solving strategies and/or complicated case studies. This technique is used to get students to use higher level thinking and justify their reasoning (Sunita M Dol and Dr. S. A. Halkude, 2017, Sunita M Dol, S. A. Halkude, 2016).

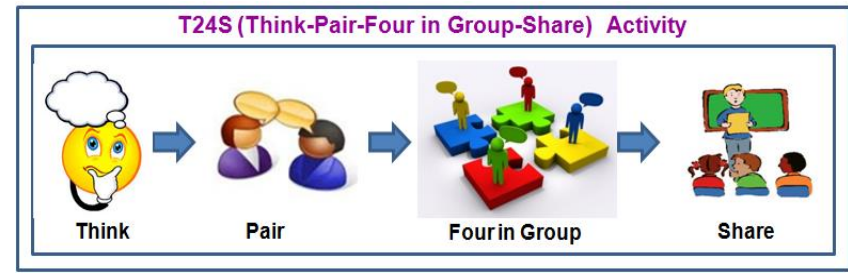

Fig. 4 Think-Pair-Four in group-Share Activity (T24S)

T21S considered for In-Class activity is given here (Sunita M Dol and Dr. S. A. Halkude, 2017).

Team Phase: Think about the application and list at least two entities and relationship between them. Write down the table (relations) contents also.

Pair phase: Indentify the constraints that can be added in the relations considered in Team phase.

Individual phase: Write the SQL command using DDL. Share phase: Share the solution in the class.

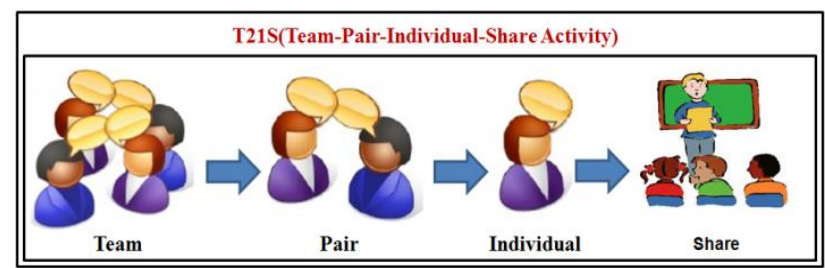

Fig. 5 T21S

\section{Results and Feedback}

The graph for the assignment submission marks is given in figure 6 . In each video, assignment is given at the end and students are supposed to submit the assignment before coming to the classroom for in-class activity. 


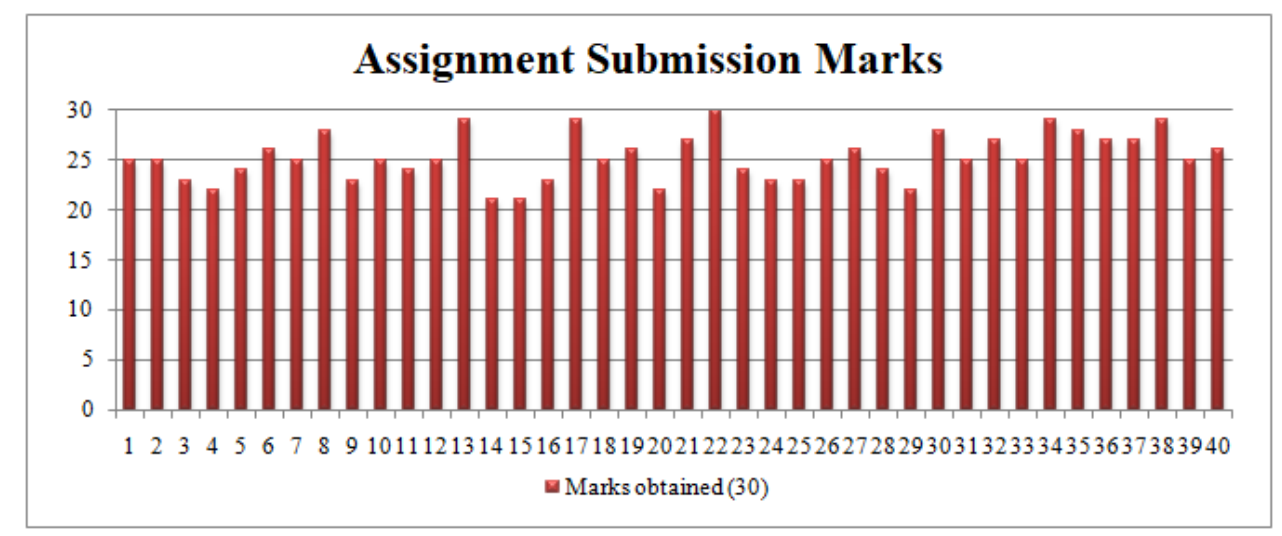

Fig. 6 Assignment Submission Marks

Assignment marks analysis is given in table 2. There are three assignments of total marks 30 . From this table it is observed that 18 students got above 25 marks, 17 students above 20 and 5 students above 15 .

Table 2. Assignment Marks Analysis

\begin{tabular}{|c|c|}
\hline Marks & No. of Students \\
\hline$>=90$ & 12 \\
\hline$>=80$ & 18 \\
\hline$>=70$ & 10 \\
\hline
\end{tabular}

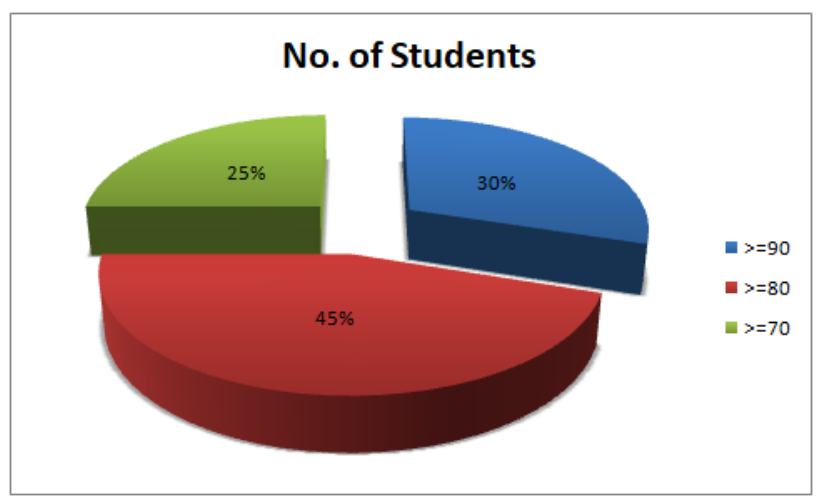

Fig. 7 Assignment Marks Analysis graph

\section{Conclusions}

Here use of self created video is used to implement the Flipped Classroom Activity for the topic SQL of Database Engineering. For out-of-class activity, self created videos with fixed template containing learning outcome, reflection spot, assignment and references are considered. In in-class activity, various active learning strategies like Think-PairShare, Peer Instruction, Team-Pair-Solo and T21S (TeamPair-Individual-Share) are used to check the understanding of the topic. Assignment submission showed more than 50\% learning due to this flipped classroom activity.

\section{References}

Sunita M Dol (2018) Animated Flowchart with Example Followed by Think-Pair-Share Activity for Teaching Algorithms of Engineering Courses, IEEE International Conference on Technology for Education (T4E-2018)

Ping Zhang, Lin Ding, and Eric Mazur (2017) Peer Instruction in introductory physics: A method to bring about positive changes in students' attitudes and beliefs

Sunita M Dol (2017) GPBL: An Effective way to Improve Critical Thinking and Problem Solving skills in Engineering Education, Journal of Engineering Education Transformation. DOI: $10.16920 /$ jeet/2017/v30i3/110523

Sunita M Dol and P. S. R. Patnaik (2017) SysPro: An Android Mobile Application for Effective Teaching in System Programming Course, Journal of Engineering Education Transformation. DOI: $10.16920 /$ jeet/2017/v0i0/111765

Sunita M Dol and Trupti S Indi (2017) Open Educational Resource (OER): C-Programming Handout based Lab Session using MOODLE for Engineering Education, Journal of Engineering Education Transformation. DOI: $10.16920 /$ jeet/2017/v0i0/111816

Trupti S. Indi, Sunita M Dol (2017) HBL for Effective Implementation of Problem Statements during Lab Session, Journal of Engineering Education Transformation. DOI: 10.16920/jeet/2017/v30i3/110524

Sunita M Dol and Dr. S. A. Halkudem(2017) An Effective Ways to Improve Problem Solving Skill using TPS, T24S and T21S: A Case Study, Journal of Engineering Education Transformation. DOI: $10.16920 /$ jeet/2017/v30i3/110570

Zamzami Zainuddin and Siti Hajar Halili (2016) Flipped Classroom Research and Trends from Different Fields of Study, International Review of Research in Open and Distributed Learning .

Christopher Nwosisi, Alexa Ferreira, Warren Rosenberg, and Kelly Walsh (2016) A Study of the Flipped Classroom and Its Effectiveness in Flipping Thirty Percent of the Course Content, International Journal of Information and Education Technology, Vol. 6, No. 5, May 2016

Lynne Drake, Micaela Kayser and Robin Jacobowitz (2016) The Flipped Classroom. An Approach to Teaching and Learning, Accessed from https://www.newpaltz.edu/media/the-benjamin-

center/P.Brief_2020Vision-Flipped\%20classroom.pdf on 25 July 2018

Sunita M Dol, S. A. Halkude (2016) T24S: Modfified TPS Activity for Mathematical Course to Improve Students' Fundamental Knowledge, Journal of Engineering Education Transformation, DOI: 10.16920/jeet/2016/v0i0/85538 Link: http://www.journaleet.org/index.php/jeet/article/view/85538

Trisha Vickrey, Kaitlyn Rosploch, Reihaneh Rahmanian, Matthew Pilarz, and Marilyne Stains (2015) Research-Based Implementation of Peer 
Instruction: A Literature Review, CBE Life Sci Educ. 2015 Mar 2; 14(1). doi: $10.1187 /$ cbe.14-11-0198

J. Morice N. Michinov M. Delaval A. Sideridou V. Ferrières (2015) Comparing the effectiveness of peer instruction to individual learning during a chromatography course, https://doi.org/10.1111/jcal.12116

Dr. S. A. Halkude and Sunita M. Dol (2015) An Active Learning Strategy Think-PairFree Open Source Software-Share to Teach Engineering Courses, Journal of Engineering Education Transformation, ISSN 23492473 (Print), eISSN 2394-1707 (Online), 413-418

Sara Arnold-Garza (2014) THE FLIPPED CLASSROOM TEACHING MODEL AND ITS USE FOR INFORMATION LITERACY INSTRUCTION, Communications in Informatiuon Litercy

Sunita B. Aher and Dattatray P Gandhmal (2014) $\mathrm{TP}_{\mathrm{Foss}} \mathrm{S}$ : A Modified TPS Technique to Improve Student's Conceptual understanding of Compiler Construction Course, T4E-2014

Sunita M Dol (2014) TPS(Think-Pair-Share) : An Active Learning Strategy to Teach Theory of Computation Course, International Journal of Educational Research and Technology P-ISSN 0976-4089; E-ISSN 22771557, IJERT: 5 [4], 62-67

Aditi Kothiyal et. al. (2013) Effect of Think-Pair-Share in a Large CS1 Class: $\quad 83 \% \quad$ Sustained $\quad$ Engagement, ICER'13, http://www.it.iitb.ac.in/ sri/papers/tps-icer2013.pdf.

Htwe, T. T., Sabaridah, I., Rajyaguru, K. M., \& Mazidah, A. M. (2012) Pathology crossword competition: An active and easy way of learning pathology in undergraduate medical education, Singapore Medical Journal, 53(2)

Tolga Gok (2012) THE IMPACT OF PEER INSTRUCTION ON COLLEGE STUDENTS' BELIEFS ABOUT PHYSICS AND CONCEPTUAL UNDERSTANDING OF ELECTRICITY AND MAGNETISM, International Journal of Science and Mathematics Education

Saxena, A., Nesbitt, R., Pahwa, P., \& Mills, S. (2009) Crossword puzzles: active learning in undergraduate pathology and medical education., Archives of Pathology \& Laboratory Medicine, 133(9), 1457-62.

Graffam, B. (2007) Active learning in medical education: strategies for beginning implementation, Medical Teacher, 29(1), 38-42

Roche, V. F., Alsharif, N. Z., \& Ogynbadeniyi, A. M. (2004) Reinforcing the relevance of chemistry to the practice through the "Who wants to be a Med Chem Millionaire?", American Journal of Pharmaceutical Education, 68(5), 116.

Michael Prince (2004) Does Active Learning Work? A Review of the Research, Journal of Engineering Education.

Bonwell, C. C., \& Eison, J. A. (1991) Active learning: Creating excitement in the classroom. Washington, DC: School of Education and Human Development, George Washington University.

Dimmock, J. R. (2000) Problem solving learning: Applications in medicinal chemistry, American Journal of Pharmaceutical Education, 64, 44-49.

Bailey, C M. et.al. (1999) Educational puzzles for understanding gastrointestinal physiology, The American Journal of Physiology, 1999, vol. 276, n. 6 Pt 2, p. S1-S18. PMid:16211663.
Jeanette Villanueva. Flipped Inclusion Classroom: An Action Research. Accessed from https://scholarspace.manoa.hawaii.edu/bitstream/10125/40822/1/Flipped_I nclusion_Classroom_Action_Research_Jeanette_Villanueva.pdf on 25 $\underline{\text { July } 2018}$

Donna Feledichuk \& Andrew Wong. The Impact of a Flipped Classroom on International Student Achievement in an Undergraduate Economics Course. Accessed from https://cloudfront.ualberta.ca//media/arts/research/april/flippedclassroom.pdf on 25 July 2018

Lakmal Abeysekera, Phillip Dawson (2015) Motivation and cognitive load in the flipped classroom: definition, rationale and a call for research, Accessed from http://www.tandfonline.com/doi/abs/10.1080/07294360.2014.934336\#.VQ EhCIGUfYk on 25 July 2018. 